\title{
SOCIAL NETWORK ANALYSIS OF CONSTRUCTION COMPANIES OPERATING IN INTERNATIONAL MARKETS: CASE OF TURKISH CONTRACTORS
}

\author{
Bartug Kemal AKGUL ${ }^{\mathrm{a}}$, Beliz OZORHON ${ }^{\mathrm{b}}$, Irem DIKMEN ${ }^{\mathrm{a}}$, M. Talat BIRGONUL ${ }^{\mathrm{a}}$ \\ ${ }^{a}$ Department of Civil Engineering, Middle East Technical University, 06800 Ankara, Turkey \\ ${ }^{b}$ Department of Civil Engineering, Bogazici University, 34342 Bebek, Turkey
}

Received 07 Apr 2015; accepted 26 May 2015

\begin{abstract}
Investigation of market entry strategies is critical for the success of international contractors. Establishing partnerships is among the most effective vehicles of operating in international markets. The major objective of this paper is to analyze the partnership behavior of contractors in overseas projects. In this respect, social network analysis (SNA) was used to better understand the collaborative project networks in different markets and for projects of differing sizes. A database was developed based on the collaborative international construction projects where Turkish firms and their non-Turkish partners were involved. A total of 449 projects carried out in 46 countries were used for the analysis. The findings of the study suggest that contractors adopt different strategies depending on the market and project characteristics. The majority of the companies tend to remain in the same markets; they keep working with the same partners or choose local partners; and engage with multiple partners in more complex projects. This study is expected to help contractors reflect on their internationalization decisions and devise appropriate strategies to establish project networks.
\end{abstract}

Keywords: construction management, social network analysis, collaborative project networks, Turkish construction industry, company relationships, collaboration strategies, partnership preferences.

\section{Introduction}

Management of construction projects is considered problematic due to their complexity. It can be asserted that this complexity is caused by the dispersed structure of the construction industry (Korkmaz, Singh 2012). Given the increasing competition in the construction business, construction companies engage in collaborations with one or more companies especially in large projects (Dimitros 2010). Since the international projects are more sensitive due to their higher uncertainties, barriers, and regional risks, they are more prone to have problems (Park et al. 2011). For this reason, collaboration is a commonly used practice in the international construction for reducing presumed risks (Son et al. 2010; Park et al. 2011). Collaborative practices among construction firms have also been studied by the researchers to a large extent.

The studies on collaborative construction projects focus on both domestic projects (Dimitros 2010) and international projects (Ozorhon et al. 2010; Park et al. 2011; Park, Han 2012). Various issues regarding project networks have been investigated so far including partner selection and partner fit (Geringer 1991; Luo 1998; Yan, Duan 2003; Ozorhon et al. 2008; Radziszewska-Zielina 2010), subcontractor selection (Ulubeyli et al. 2010), performance of collaborative arrangements (Mohamed 2003; Choi, Beamish 2004; Ozorhon et al. 2010; Chen et al. 2012) and cultural differences between the partnering firms and the host country (Park, Ungson 1997; Ozorhon et al. 2007). The majority of the current literature on project collaborations concentrates on manufacturing industries. Besides, partnership behavior of contractors in international markets has not yet been analyzed. The major objective of this paper is to examine the strategies of contractors that establish collaboration networks in overseas projects. In this respect, social network analysis (SNA) has been employed on data concerning the international project networks of Turkish contractors. SNA has been selected as an appropriate tool since it enables the investigation of network of relationships in construction projects (Pryke 2004). The required data is obtained from the Turkish Ministry of Economy (2014). The project database includes all of the international construction works undertaken by the Turkish contractors from 1972-2013. The projects that involved partnerships were extracted from the database and categorized considering the size of the projects and the markets of operation. A general network along with a budget-based and market-based network was constructed. This approach was

Corresponding author: Bartug Kemal Akgul

E-mail: bartugkemalakgul@gmail.com 
adopted to enable the observation of the differences in collaboration strategies depending on the project characteristics and market conditions.

\section{Inter-firm collaboration in global construction}

Global construction has become attractive yet more competitive for the construction firms. Despite their benefits, international projects are highly risky for the contractors. In order to succeed in international projects, engineering and construction firms should combine several firm-specific factors and home-specific factors (Paek, Kim 1993). Wong et al. (2010) stated that contractors face many uncertainties in international projects and their success depends on how well they cope with those uncertainties. Korkmaz and Messner (2008) examined the competitive positioning and continuity in international markets and concluded that construction firms tend to pursue consistent strategies in international markets while they adjust these strategies according to market demands and global tendencies. Inter-firm collaborations have become an integral part of the global construction due to their importance in creating competitive advantage. Project partnership is an important way of collaboration and it enables firms to complement resources and competencies. According to Nielsen (2002), there are several advantages obtained through partnerships such as risk/cost sharing, transfer of knowledge related capabilities, improved competition, access to new markets, and easier adaptation to internationalization.

International construction projects are just one of the activities that involve multinational participants from different political, legal, economic, and cultural backgrounds (Chan, Tse 2003). The smooth operation such projects relies heavily on the interaction between the partners in making strategic and operational decisions (Sridharan 1997). Partner selection becomes a critical success factor for collaborative projects. In some cases, due to the local regulations and cultural differences, foreign companies prefer to establish joint ventures with local companies. This allows faster and easier access to the local market and local distribution systems, improved knowledge of the local economy, improved access to local human resources, preferential treatment from the host country relative to issues like the repatriation of dividends, the registering of investment to increase the capital base and the securing of government contracts and work permits (Beamish 1988). Therefore, companies devise strategies based on the project and market specific characteristics and form networks accordingly.

\section{Research methodology}

The relationships between social actors are expressed by social networks as graphical representations (Kim et al. 2011). Although the concept is originated from sociology in order to classify human societies, it has been used to explain various relationships between many types of social actors (Moreno 1937). SNA can be described as a technique which is used for identifying, expressing, and visualizing these social behaviors. The relationship data of the actors are transformed into visual graphs and complemented by its quantitative measures (Kim et al. 2011; Kilduff, Tsai 2003; Li et al. 2011). Thereby, this technique aims to disclose the positions and characteristics of the actors in the network, in addition to the evaluation of the general structure of the network.

The most remarkable feature of SNA is its use of own measures to analyze and interpret the networks. In this way, SNA enables to make comparison between various networks since it uses the same criteria and measures to study on them (Pryke 2004). Due to the fact that the analysis of single networks can be cursory, this comparison ability constitutes a crucial attribute of SNA.

In this technique, the social actors are defined by the nodes and the relationships between them are defined by ties (Chinowsky et al. 2008). The ties may have some attributes that help to represent the relationships in a more accurate way. If there is orientation in the relationship from one actor to another, directed ties are placed in between these actors to imply this orientation. Besides use of directed ties, undirected ties are used to express reciprocal relationships. In other words, undirected ties are interested in the existence of the relationships. These ties can also be named as asymmetrical and symmetrical ties respectively (Meese, McMahon 2012). Besides the directed or undirected indication of relations, weights could also be assigned to the ties to indicate their frequencies. These networks can be named as weighted or valued networks (Meese, McMahon 2012).

When the ability to use nodes and ties for various types of actors and relationships is combined with these features of ties, SNA becomes an intriguing issue for many researchers from different fields. Therefore, many other sectors including health (Meltzer et al. 2010), education (Korkmaz, Singh 2012; Li et al. 2010), projectbased industries (Divjak et al. 2010), and manufacturing (Kim et al. 2011; M'Chirgui 2007) have benefited from SNA. Since there can be many relationships in construction industry that can be expressed as networks, SNA has been commonly used by the researchers of the construction management field in the recent years (Larsen 2011). Although SNA has been studied in many different areas, it can be defined as a newer technique for construction industry. The studies in this field mainly investigate the communication between the members of project teams or companies (Farshchi, Brown 2011; Javernick-Will 2011; Loosemore 1998; Meese, McMahon 2012; Tang 2012; Zhang et al. 2013) by using SNA. On the other hand, there are also some studies carried out such as the success of application of SNA in the construction industry (Ling, Li 2012), establishment of the network of construction trades by SNA (Wambeke et al. 2012), and SNA use in organizational team formation (Li et al. 2011; Lin 2012).

Chinowsky et al. (2008) claimed that the networks can be found in every professional activity. The construction industry involves many parties that need to work in 
a harmonic way to complete project successfully. These parties inherently include many types of relationships between them that lead construction of various networks. For that reason, construction sector has become a favorable field for the application of SNA. Therefore, the relationships between workers, projects teams, staff members, companies, etc. in this sector can be studied by the help of SNA. Although the relationship between humans is a more preferred study type, the relationships between companies have drawn less attention in this field (Park et al. 2011). Nevertheless, the SNA is a successful methodology to explore the firm-level relationships between construction companies (Li et al. 2011).

\subsection{Measures of SNA}

The SNA measures can be considered in two main levels: network and node levels (Kim et al. 2011). While the former one gives information about the overall network, latter explains the individual performances of the actors in the network. There are numerous measures under these main categories. However, since this study focuses on company level relationships, some of these measures were considered as insignificant. The following explain the significant measures used in this study.

Density, is a network level measure, which reveals the connectedness of the network (Farshchi, Brown 2011; M'Chirgui 2007; Pryke 2005). In other words, it can be seen as an indicator for the amount of relations between the actors (Chinowsky et al. 2008). It is measured by taking the ratio of existing ties to the possible ties in the network (Dimitros 2010; Farshchi, Brown 2011; Kilduff, Tsai 2003). While calculating the density, all the nodes in the network are assumed to be connected to each other in order to calculate the possible ties (Chinowsky et al. 2008). The density of a network ranges between 0 and 1 ; as it becomes closer to 1, the network becomes denser (M'Chirgui 2007; Pryke 2005; Ruan et al. 2012).

The total number of sub groups in the network is expressed by connected components. The value shows the amount of isolated groups in the networks whose members are only connected to other members in the same group. Basically, it can be asserted that as the number of connected components gets higher, the network becomes more dispersed (Bastian et al. 2009). Although, this measure may remain incapable by itself, it can be used to obtain various interpretations when combined with other network properties.

Degree and weighted degree are node level measures. The former one shows the number of the nodes that an actor is connected in the network and is calculated by summing up the number of ties of the node. On the other hand, the latter shows the total number of relationships of an actor if the ties have the ability to indicate the frequencies. In the networks constituted by directed ties, the incoming and outgoing relationships are calculated separately by calculating their in-degree and out-degree values (Dimitros 2010). In this study, since the weighted and undirected ties are used while constructing the networks, only degree and weighted degree values of nodes are considered. They can be utilized in comparing the nodes in the same network. Although these are node level measures, they can also be used in network level by taking the average of both degree and weighted degree values of all the nodes in the network. In this way, general tendency of the network can be obtained. However, the average values for networks with different sizes should not be compared, due to the fact that the size may significantly affect them.

Betweenness centrality is another node level measure, which is another indicator of the importance of a node. It measures the node's ability to connect other nodes in the network (Loosemore 1998). In calculation of this measure, total number of shortest paths between all node pairs in the network plays an important role. When a node's betweenness centrality is considered, it is calculated by taking the proportion of shortest paths that goes through that node to the all shortest paths in the network (Park et al. 2011). Despite the fact that this measure is more feasible in the networks that are constructed by people, it can be applicable in company-level networks since they are also represented by people.

According to Bastian et al. (2009) eigenvector centrality measures the importance of a node in the network based on its connections. The neighbor nodes' being at the center affects the eigenvector centrality value of a node (Wambeke et al. 2012). In other words, the properties of its neighbors also influence the significance of a node in the network. In calculation of this measure, relative scores in between 0 to 1 are assigned to the actors in the network based on all the connections in the network. While determining these values, power iteration is applied to find converged values. As the score gets higher, the node becomes more significant in the network.

\subsection{Data collection}

The data of all overseas projects that were performed by Turkish contractors were obtained from the Turkish Contracting and Engineering Services Division of the Turkish Ministry of Economy (2014). The database includes 7272 projects, in which the names of the performing company, host country, job name, contract date, region, activity area, and budget of each project are available. Since the study seeks collaborative projects, the data was first classified based on how the projects were delivered, i.e. by a sole contractor or through a partnership. The projects that were performed by single entities, consultancy works, and other services were eliminated to obtain only the collaborative projects. The data was further refined to discard the duplicated projects and the projects of group companies. The final number of projects eligible for the study was found to be 449 . The projects involve partnerships between Turkish companies and their Turkish or non-Turkish partners. After the classification process, Gephi (Bastian et al. 2009) was used to construct and 
study the networks. Gephi is SNA software which was preferred due to its user-friendly interface and remarkable visual performance.

\section{Research findings}

Each company in the data was introduced to the software by defining its label and with an assigned ID number. The ID's of the companies are not editable and they are used as given by the software. There are 254 companies in the data and their ID's change from 51 to 309. However, there are five ID's which do not represent any company since they were removed from the network. In the same manner, the relationships between the companies were uploaded by defining their targets and sources. All the ties are defined as undirected due to collaboration's reciprocal nature. The weights of these ties are also adjusted accordingly to represent the relationship between two companies that are collaborated in more than one project. If more than two companies were involved in a project, a tie is entered for each pair.

\subsection{General network}

The general network of contractors based on their collaborative performances on international projects was constructed with a total of 449 projects. In this network, there are 254 companies and 232 ties. These projects are performed in 46 host countries.

As it can be seen in Figure 1 and Table 1, the general network has a dispersed structure. The density is very low and there are many sub groups in the network. This situation can be explained by the high number of companies in the network and the disconnectedness of these companies and their groups. In other words, a very large number of possible relationships were not presented in the network.

Figure 1 shows the ties between companies. Different colours are assigned to companies depending on

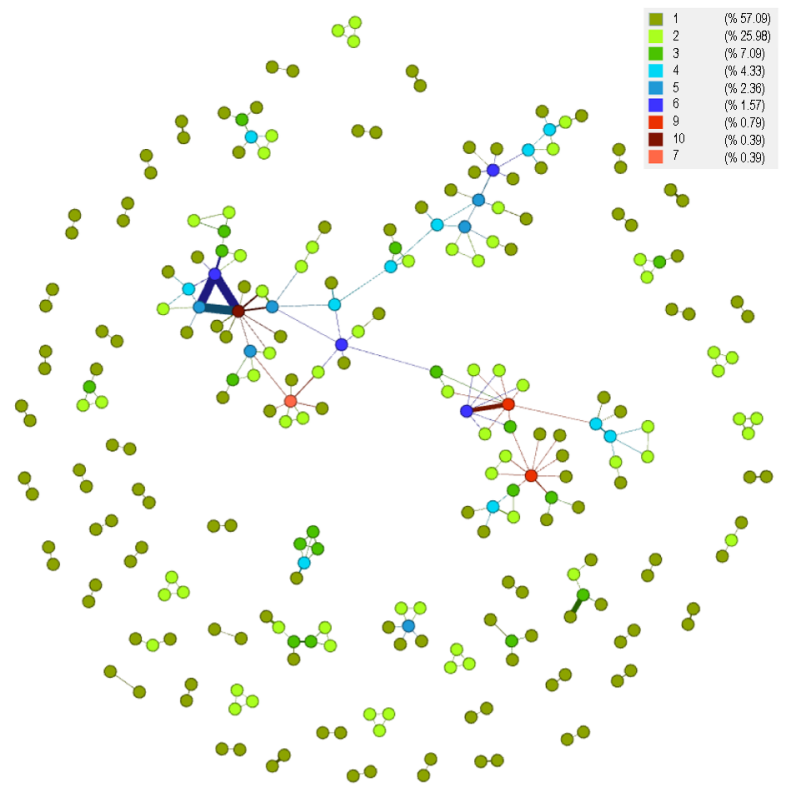

Fig. 1. General network
Table 1. Network level measures for the general network

\begin{tabular}{ll}
\hline \multicolumn{1}{c}{ SNA measure } & Value \\
\hline Density & 0.007 \\
Average Degree & 1.835 \\
Average Weighted Degree & 5.216 \\
Connected components & 61 \\
\hline
\end{tabular}

the extent they were connected. The same principle is valid for the rest of the figures. Figure 1 also provides the percentage values based on the number of collaborations the companies have established. It is observed that $57.1 \%$ of the companies have collaborated with only one partner; whereas $1.6 \%$ of those have formed partnerships with five companies. Moreover, the companies have collaborated with 1.827 companies on average. On the other hand, when the weighted degrees are considered, it can be seen that there is a tendency to make collaboration in more than one project since average weighted degree is approximately 3 times larger than the average degree.

When the node level results are considered, the companies with most successful results based on various measures are given in Tables 2-5. The degree measures are shown in Table 2. Company-77 that has collaborated with 10 different companies in the international market has the highest number of partners. When Figure 1 is examined in a detailed way, it can be seen that more than $80 \%$ of the companies have collaborated with less than two partners. Therefore, collaborating with multiple companies is not a common practice among the Turkish

Table 2. The highest-degree companies of the general network

\begin{tabular}{cc}
\hline Company ID & Degree \\
\hline 77 & 10 \\
145 & 9 \\
262 & 9 \\
117 & 7 \\
130 & 6 \\
135 & 6 \\
161 & 6 \\
268 & 6 \\
\hline
\end{tabular}

Table 3. Companies with the highest weighted-degree scores

\begin{tabular}{cc}
\hline Company ID & Weighted degree \\
\hline 77 & 137 \\
161 & 124 \\
177 & 111 \\
192 & 36 \\
145 & 35 \\
193 & 33 \\
268 & 32 \\
131 & 21 \\
\hline
\end{tabular}


Table 4. The highest betweenness centrality scores of the general network

\begin{tabular}{cc}
\hline Company ID & Betweenness centrality \\
\hline 130 & 0.0794 \\
145 & 0.0691 \\
144 & 0.0651 \\
66 & 0.0623 \\
227 & 0.0609 \\
131 & 0.0539 \\
273 & 0.0531 \\
77 & 0.0521 \\
\hline
\end{tabular}

Table 5. The highest eigenvector centrality scores of the general network

\begin{tabular}{cc}
\hline Company ID & Eigenvector centrality \\
\hline 77 & 1 \\
145 & 0.9196 \\
268 & 0.7094 \\
161 & 0.6468 \\
131 & 0.5939 \\
177 & 0.5936 \\
121 & 0.5397 \\
267 & 0.5220 \\
\hline
\end{tabular}

contractors. The experience in the international market can also be measured by the weighted degree of the companies (Table 3). Although there are some changes relative to Table 2, Company-77 retained its position. The highest values of normalized betweenness centralities for the companies in the network are shown in Table 4. The reason behind the low values is the dispersed structure of the network. The companies with highest scores are also ranked in the degree list; however, they lost their position in the weighted degree list. If the companies are represented at individual level, then the ones in Table 4 would have the highest ability to reach other companies.

As it is stated previously, the eigenvector centrality values are useful in identifying the significance of the nodes in the network. Therefore, the most important members of the general network can be seen in the Table 5, since it considers all of the relationships in the network. These companies are the most experienced and thriving companies in the international market. The structure of the network caused the efficiency of the eigenvector centrality measure to get lower. However, it is still possible to notice the effect of the specific relationships to the importance of the companies.

Based on the general network, the following results are obtained:

- Project collaboration is not a very common practice for the Turkish contractors since majority of the international projects (94\%) were performed individually. Among all projects, only $6 \%$ was undertaken through partnerships.
- The number of the companies that have established very few (less than three) partnerships in overseas projects is very high.

- Although the network has a dispersed structure, it can be asserted that the companies are in a kind of related with each other due to the existence of a major component with high number of members.

- It is possible to deduce that the companies follow various strategies. The main two types are: (i) collaborating with as many companies as possible; and (ii) engaging in many projects with only familiar and less number of partners.

\subsection{Cost-based networks}

The size of a project may directly affect the entry mode selection, i.e., whether the company will undertake the project solely or by collaborating with partners. Therefore, the study aimed at analyzing the strategies of the contractors based on the project size as well. The projects were classified under 3 different categories. While constructing these networks, it was intended to have equal number of projects as much as possible. The formed networks with this approach are summarized in Table 6.

Table 6. Information about the cost-based networks

\begin{tabular}{llc}
\hline $\begin{array}{c}\text { Network } \\
\text { name }\end{array}$ & \multicolumn{1}{c}{ Project budget (P.B) } & $\begin{array}{c}\text { Number of } \\
\text { projects }\end{array}$ \\
\hline Small & P.B $<$ \$10 million & 158 \\
Medium & $\$ 10$ Million $<$ P.B $<\$ 50$ Million & 148 \\
Large & \$50 Million $<$ P.B & 143 \\
\hline
\end{tabular}

Small Scale Project Network (SSPN) is formed by 116 different companies and it has a highly dispersed structure. When Figure 2 is examined, it can be concluded that most of the companies formed isolated groups consisting of only two or three companies. Due to this structure of the network, only the highly experienced

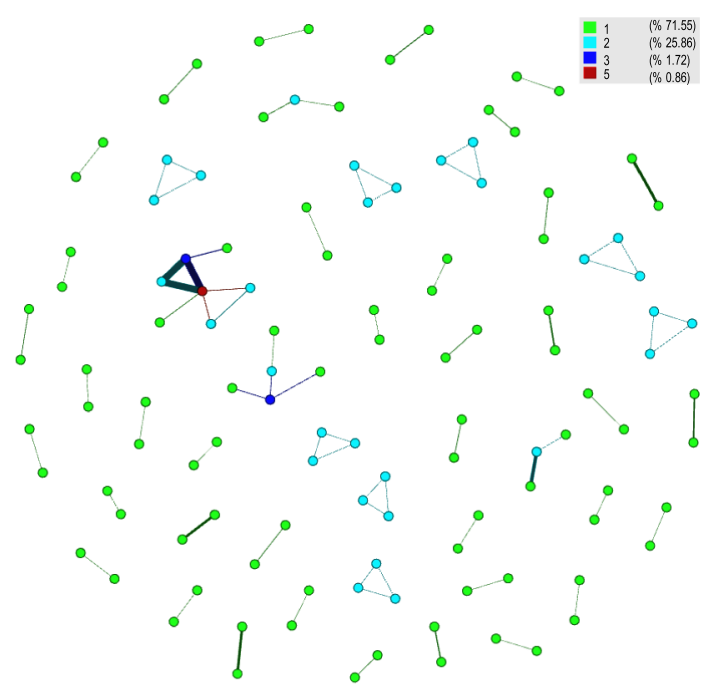

Fig. 2. Small scale project network 


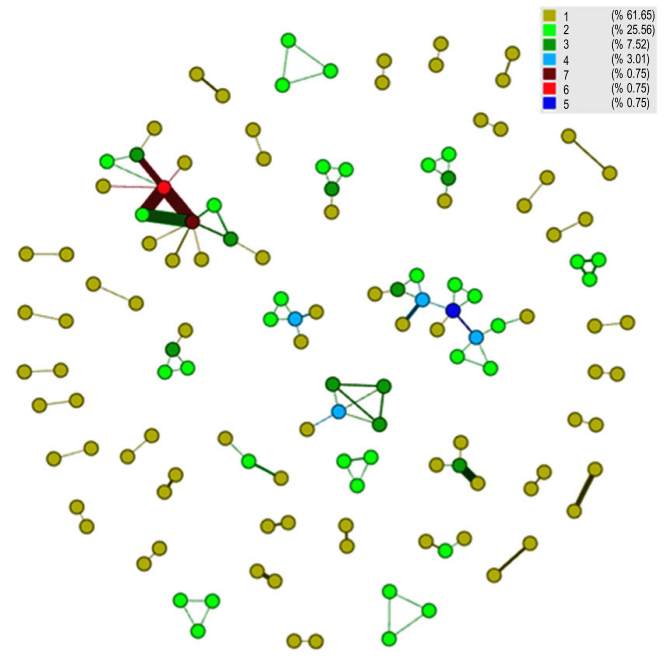

Fig. 3. Medium scale project network

ones in this network could be taken as prominent companies.

Medium Scale Project Network (MSPN) is formed by 132 different companies. As it can be seen from Figure 3, although there are more companies in MSPN, there are bunches of companies. Therefore, it can be interpreted that the structure of the MSPN is more ordered. The significant companies of this network can be found by observing the leader companies in these sub-groups with relatively high number of members.

Large Scale Project Network (LSPN) is constituted by 124 companies with least number of projects among the budget-based networks. However, when the graphical representation of LSPN in Figure 4 is examined, it can be realized that the structure has the most connected appearance among all budget-based networks. The major groups in the network have a relatively high numbers of members. Therefore, in this network, the biggest players in the market could be easily identified.

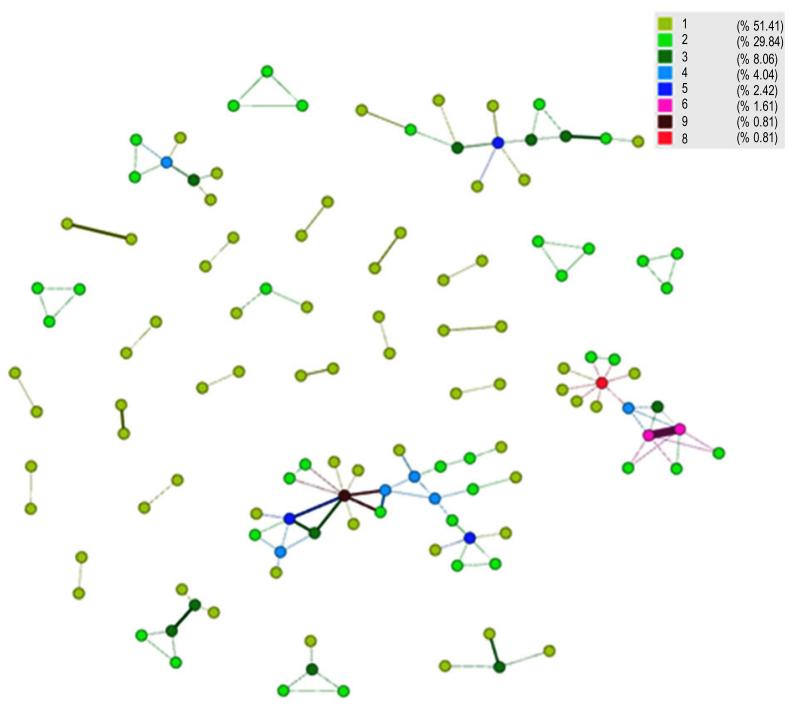

Fig. 4. Large scale project network
Various patterns of structures come into the picture in each of the budget-based networks as expected. Based on the results of the budget-based networks, it can be stated that:

- Collaboration becomes more preferable when the project size gets bigger. The main reason behind this situation could be seen as the capability of the firms to perform small scale projects individually.

- In the same manner, the number of partnerships between three or more companies increases in larger projects. This may be attributed to the fact that large scale projects require more specialization.

- Companies follow different strategies in different networks. For example, some companies become salient as the size of the projects gets larger. However, many companies are only active in the small scale projects and they disappear in larger ones. On the other hand, some companies stand out in all of the networks. This situation might be a result of the succesful projects with previous partners.

\subsection{Market-based networks}

The host country information was used to investigate the presence of companies in various markets. In this respect, four different markets were generated based on the countries that the Turkish contractors have operated. These markets are: Commonwealth of Independent States (CIS), Middle East, Africa, and Europe. Except the USA, all the host countries were included in one of these markets. In this way, the relationship in only one project was eliminated from the dataset. The geographical locations of the countries played a decisive role in determining the market for the remaining countries.

- CIS market: the countries which belong to the CIS constitute the largest market for the Turkish contractors. The countries in this market are: Azerbaijan, Belarus, Georgia, Kazakhstan, Kyrgyzstan, Moldova, Russia, Tajikistan, Turkmenistan, Ukraine, and Uzbekistan. The 198 projects in this market correspond to $44.1 \%$ of the data. However, these projects were performed by only 76 companies that correspond to $29.8 \%$ of the companies in the general network. Therefore, it can be concluded that the companies in this market prefer to maintain their partnership in the subsequent projects.

As it can be seen in Figure 5, the network of CIS market has a similar appearance to the general network. The major component in the network is very useful in the determination of the leading companies. Since collaborating in multiple projects is a common practice in this network, the relatively thicker edges are very helpful. Some of the outstanding companies from the general network are absent in the CIS market, which is directly related to their international strategy. On the other hand, the most active companies of this network were also among the striking ones in the general network. 


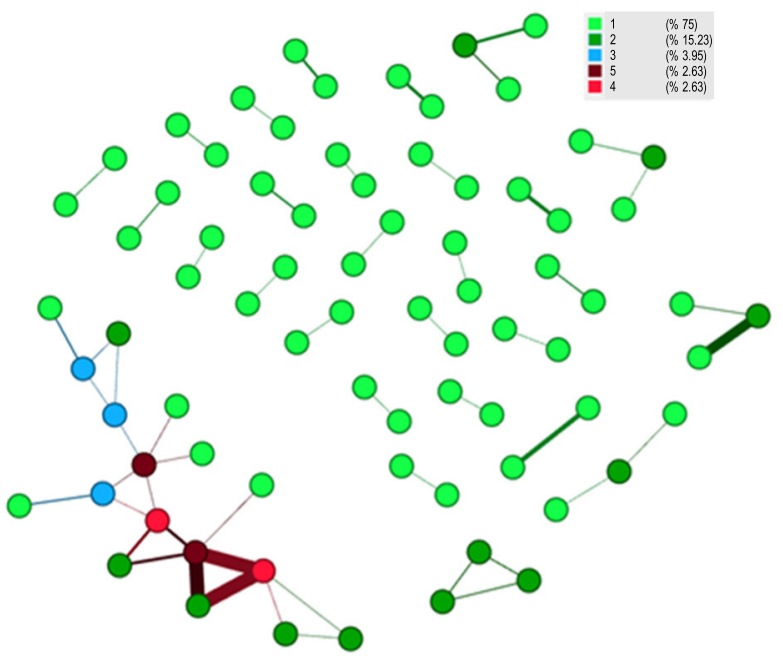

Fig. 5. CIS market network

- Middle East market: Middle East market is another attractive market for Turkish contractors. Their huge investments on construction projects with the earnings from natural resources have opened an important market in this region. Turkish contractors took the advantage of Turkey's cultural and regional proximity to the countries of this market. The countries that belong to the Middle East market are: Afghanistan, Bahrain, Iran, Iraq, Jordan, Kuwait, Oman, Pakistan, Qatar, Saudi Arabia, Syria, UAE, Turkish Republic of Northern Cyprus, and Yemen. When the number of the projects in this market is studied, it can be seen that the share of this market gets larger when the collaborated projects are considered. The total amount of collaborated projects in this market is 151 and this is approximately $33.6 \%$ of the collaborated projects in the international market. An interesting result comes out in the total number of companies in this network. 122 different companies exist in this market, resulting in $48 \%$ of the companies in the general network. Therefore, it can be stated that the companies that are willing to get into this market followed the strategy to collaborate with various companies. In this way, the connectedness of the network becomes higher despite the increase in the size and diversity of the network.

In the network provided in Figure 6, the major component is relatively larger due to its high number of members. Moreover, there is a considerable amount of groups, which consist of 4 to 7 members. This situation reveals that the aggregation between particular companies is also existent in this network. When the results of this network are examined in detail, it is seen that the missing leading companies in the previous network appears in this network as the most connected companies of the network.

- Africa market: it can be stated that Africa has played a pivotal role for Turkish contractors since it was the first gate to open the international market. However,

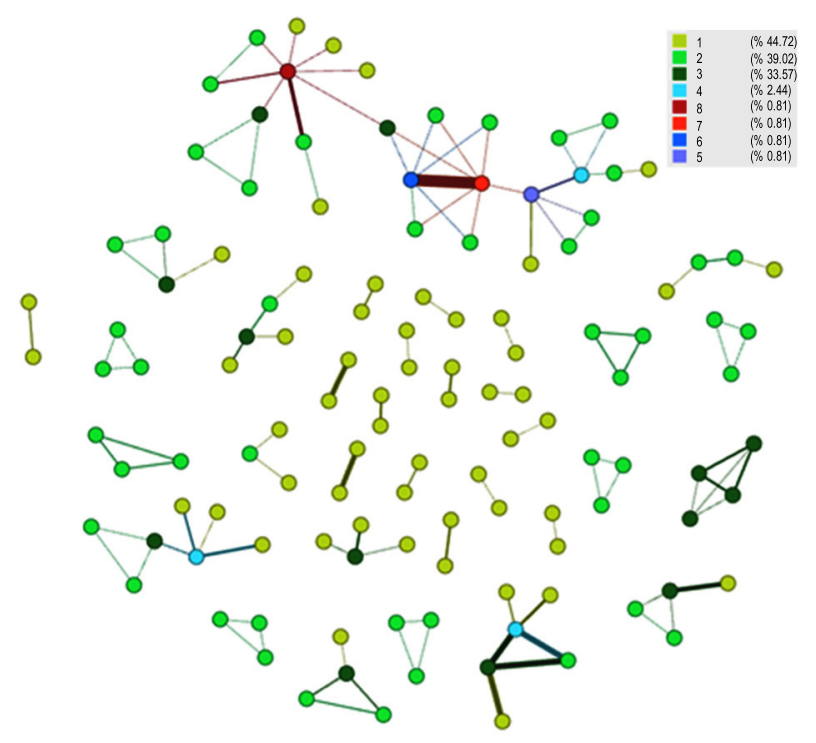

Fig. 6. Middle East market network

over the years with the economic instability due to the political problems in this region, this market lost its dominance. Nevertheless, this market has still a respectable share as far as the last 40 years is considered. The countries that belong to the Africa market are: Algeria, Egypt, Equatorial Guinea, Gabon, Ghana, Libya, Mali, Nigeria, Sudan, and Tunisia. When the collaborated projects in the Africa market are classified, it is seen that the number of projects is less than expected. There are only 64 projects in this market and this amount corresponds to a smaller portion than the share of this market. These projects were performed by a relatively high number of companies. Therefore, the network of this market has a highly separated structure, which makes it very hard to comment on the strength of the companies from collaboration point of view (Fig. 7).

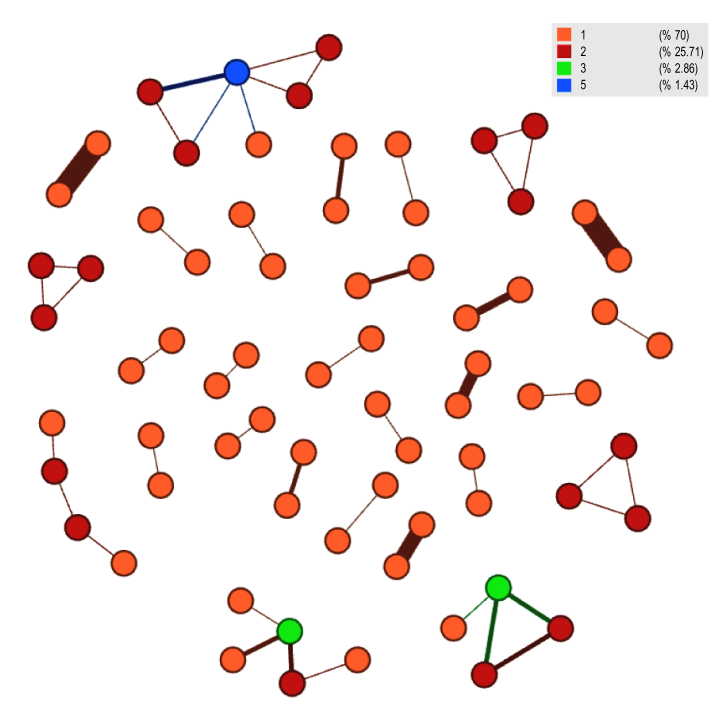

Fig. 7. Africa market network 
As it can be seen in Figure 7, other than three small groups with four to six members, all the components of the network are comprised of isolated dyads and triads. Therefore, it can be stated that identifying the leading companies could not be accurate due to the unreliable structure of the network. In these types of networks, adding or removing just one connection could completely change the results related to the importance of the nodes. The company with having highest number of relationship directly appears as the most significant member of the network. For that reason, only general information gathered from this type of network could be accepted as dependable.

- Europe market: the last market considered in this study is the Europe market. This market is a relatively newer market for Turkish contractors. The countries that are classified in this market are: Albania, Bosnia Herzegovina, Bulgaria, Kosovo, Lithuania, Macedonia, Montenegro, Poland, Romania, and Serbia. As expected, this market is the smallest one with having only 35 collaborated projects. However, a striking result shines out for the case of total number of companies. These projects were performed by 48 different companies that make this network the most dispersed network of all market-based networks. Therefore, the structure of the Europe market is not much copious in making deductions.

The Europe network is depicted in Figure 8. As in the case of Africa market, making individual comments about the companies is not very meaningful for Europe market. The companies in the subgroup on top of Figure 8 are defined as the most outstanding companies of the market.

Based on the findings of the market-based networks, it is demonstrated that the companies follow various strategies in different markets. The main findings from these networks can be summarized as:

- The reasonable and comprehensive results for the nodes were obtained only in the CIS and Middle

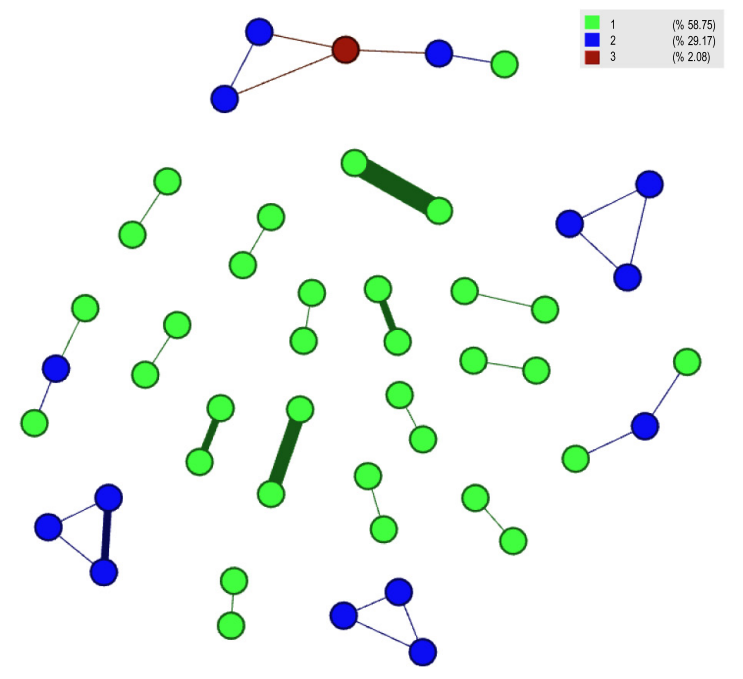

East market. The collaboration network of Africa and Europe did not allow identification of the leading companies.

- The tendency of companies in the CIS market is to establish partnerships and maintain them in the future projects. Although the number of companies in this market is less, the active ones have a high possibility to find new opportunities.

- Collaboration is a more common practice in the Middle East market. In this market, companies tend to establish partnerships. The legal necessities to collaborate with local companies can be considered as the main motivation behind this situation.

- Different companies are observed to be dominant members of these two networks. This means that the companies determine their target market and focus on the projects on this market. The outstanding companies of the general networks are also leading ones in the CIS and Middle East market.

- Although the share of Africa market is still notable, its collaboration network has a small and dispersed structure. This situation can be explained by the less complicated nature of the projects, less specialization requirement in these projects and the encouragement of individual bidders in this market. Therefore, it can be asserted that the Turkish contractors prefer to perform projects solely in this market.

- Since the number of projects in the Europe market is not sufficient to make interpretation about the Turkish contractors' collaborative performance, the most accurate comment is that the Turkish contractors do not have a considerable presence in the Europe market. This is partly due to the severe restrictions such as high competitiveness, high quality expectancy and limitations in employment conditions of the workers that discourage Turkish contractors from doing business in Europe.

It should also be noted that the findings of the study were shared with three industry practitioners, including assistant general manager in a large construction company; a regional manager of a multinational company; and a senior manager from Turkish Contractors Association (2014). The comments regarding the project networks have been finalized based on discussions with these experts.

\section{Conclusions}

Due to the increasing competition in the global construction market, companies engage in collaborative arrangement to enter new markets and sustain their presence in those markets. This study investigates the partnership behavior of Turkish contractors in international projects. In this respect, SNA was used as a tool to demonstrate its applicability to examine strategies of contractors in project networks and understand how they behave in terms of their strategic positioning.

Fig. 8. Europe market network 
Based on the findings of this study, it was observed that the Turkish contractors do not hesitate to expand their business abroad. They generally prefer to undertake international projects on their own; they rarely establish partnerships with other firms. In case of collaborating with others, they pursue different strategies depending on the project size and the host market. For example, they collaborate with multiple firms in large scale projects; they find local partners in markets where they have less experience; and they keep partners of previous successful projects. Considering the increasing level of competition in overseas markets and complexity of the projects, companies can no longer operate on their own. In order to sustain growth in international markets, Turkish contractors are advised to engage in more collaborations. This will also help transfer know-how from companies that are experienced in technology-intense projects.

It should be noted that this study is limited by the experiences of Turkish contractors and the markets they operate in. However, the study demonstrates the use of SNA in investigating the strategic positioning of international contractors. A similar analysis may be carried out for companies from other countries. Another issue is related to the time span that is considered; the study examines the overseas projects completed within the last 40 years. Therefore, the data includes some companies that do not any longer exist. A further study could focus on a shorter time period (e.g. last decade) to enable more accurate analysis. Besides, SNA may be applied to investigate the project networks in domestic projects.

\section{Acknowledgements}

The authors would like to express their gratitude to Turkish Contracting and Engineering Services Unit of Turkish Republic Ministry of Economy for their provision of information and their interest in this study.

\section{Disclosure statement}

The authors do not have any competing financial, professional, or personal interests from other parties.

\section{References}

Bastian, M.; Heymann, S.; Jacomy, M. 2009. Gephi: an open source software for exploring and manipulating networks [online], [cited 15 April 2014]. Available from Internet: https://gephi.org/publications/gephi-bastian-feb09.pdf

Beamish, P. W. 1988. Multinational joint ventures in developing countries. London: Routledge. 14 p.

Chan, E. H. W.; Tse, R. Y. C. 2003. Cultural considerations in international construction contracts, Journal of Construction Engineering and Management 129(4): 375-381.

https://doi.org/10.1061/(ASCE)0733-9364(2003)129:4(375)

Chen, W. T.; Chen, T. T.; Lu, C. S.; Liu, S. S. 2012. Analyzing relationships among success variables of construction partnering using structural equation modeling: a case study of Taiwan's construction industry, Journal of Civil Engineering and Management 18(6): 783-794. https://doi.org/10.3846/13923730.2012.735062
Choi, C. B.; Beamish, P. W. 2004. Split management control and international joint venture performance, Journal of International Business Studies 35: 201-215. https://doi.org/10.1057/palgrave.jibs. 8400078

Chinowsky, P.; Diekmann, J.; Galotti, V. 2008. Social network model of construction, Journal of Construction and Engineering Management 134(10): 804-812.

https://doi.org/10.1061/(ASCE)0733-9364(2008)134:10(804)

Dimitros, K. 2010. Greek construction firms formation and topological analysis of a collaboration network, International Research Journal of Finance and Economics 53: 168-177.

Divjak, B.; Peharda, P.; Begicevic, N. 2010. Social network analysis of successful partnerships in innovative international projects, in International Conference on Information Technology Interfaces (ITI 2010), 21-24 June 2010, Cavtat, Dubrovnik, Croatia, 441-446.

Farshchi, M. A.; Brown, M. 2011. Social networks and knowledge creation in the built environment: a case study, Structural Survey 29(3): 221-243. https://doi.org/10.1108/02630801111148202

Geringer, J. M. 1991. Strategic determinants of partner selection criteria in international joint ventures, Journal of International Business Studies 22(1): 41-62. https://doi.org/10.1057/palgrave.jibs.8490291

Javernick-Will, A. 2011. Knowledge-sharing connections across geographical boundaries in global intra-firm networks, Engineering Project Organization Journal 1(4): 239-253. https://doi.org/10.1080/21573727.2011.613458

Kilduff, M.; Tsai, W. 2003. Social networks and organizations. London, England: SAGE Publications Ltd. 172 p.

Kim, Y.; Choi, T. Y.; Yan, T.; Dooley, K. 2011. Structural investigation of supply networks: a social network analysis approach, Journal of Operations Management 29(3): 194-211. https://doi.org/10.1016/j.jom.2010.11.001

Korkmaz, S.; Messner, J. I. 2008. Competitive positioning and continuity of construction firms in international markets, Journal of Management in Engineering 24(4): 207-216.

https://doi.org/10.1061/(ASCE)0742-597X(2008)24:4(207)

Korkmaz, S.; Singh, A. 2012. Impact of team characteristics in learning sustainable built environment practices, Journal of Professional Issues in Engineering Education and Practice 138(4): 289-295. https://doi.org/10.1061/(ASCE)EI.1943-5541.0000107

Larsen, G. D. 2011. Understanding the early stages of the innovation diffusion process: awareness, influence and communication networks, Construction Management and Economics 29: 987-1002. https://doi.org/10.1080/01446193.2011.619994

Li, W.; Wang, X.; Yu, M. 2010. A research on collaboration knowledge construction in the virtual learning community by social network analysis, in International Conference on Educational and Information Technology (ICEIT 2010), 17-19 September 2010, Chongqing, China, 2: 323-327.

Li, Y.; Lu, Y.; Kwak, Y. H.; Le, Y.; He, Q. 2011. Social network analysis and organizational control in complex projects: construction of EXPO 2010 in China, The Engineering Project Organization Journal 1(4): 1-15. https://doi.org/10.1080/21573727.2011.601453

Lin, Y. 2012. Research on organization network model for construction project based on social network analysis, Applied Mechanics and Materials 174-177: 2001-2005.

https://doi.org/10.4028/www.scientific.net/AMM.174177.2001

Ling, F. Y. Y.; Li, S. 2012. Using social network strategy to manage construction projects in China, International Journal of Project Management 30(3): 398-406. https://doi.org/10.1016/j.ijproman.2011.05.010 
Loosemore, M. 1998. Social network analysis: using a quantitative toll within an interpretative context to explore the management of construction crises, Engineering, Construction and Architectural Management 5(4): 315-326. https://doi.org/10.1108/eb021085

Luo, Y. 1998. Joint venture success in China: How should we select a good partner?, Journal of World Business 33(2): 145-166. https://doi.org/10.1016/S1090-9516(99)80068-6

M'Chirgui, Z. 2007. The smart card firms' network positions: a social network analysis, European Management Journal 25(1): 36-49. https://doi.org/10.1016/j.emj.2006.11.002

Meese, N.; McMahon, C. 2012. Analysing sustainable development social structures in an international civil engineering consultancy, Journal of Cleaner Production 23(1): 175185. https://doi.org/10.1016/j.jclepro.2011.10.018

Meltzer, D.; Chung, J.; Khalili, P.; Marlow, E.; Arora, V.; Schumock, G.; Burt, R. 2010. Exploring the use of social network methods in designing healthcare quality improvement teams, Social Science \& Medicine 71(6): 1119-1130. https://doi.org/10.1016/j.socscimed.2010.05.012

Mohamed, S. 2003. Performance in international construction joint ventures: modeling perspective, Journal of Construction Engineering and Management 129(6): 619-626.

https://doi.org/10.1061/(ASCE)0733-9364(2003)129:6(619)

Moreno, J. L. 1937. Sociometry in relation to other sciences, Sociometry 1(1/2): 206-219. https://doi.org/10.2307/2785266

Nielsen, B. B. 2002. Determining international strategic alliance performance. Copenhagen Business School Department of International Economics and Management, Denmark, 2002. Working Paper No. 6.

Ozorhon, B.; Arditi, D.; Dikmen, I.; Birgonul, M. T. 2007. Effect of host country and project conditions in international construction joint ventures, International Journal of Project Management 25(8): 799-806. https://doi.org/10.1016/j.ijproman.2007.05.003

Ozorhon, B.; Arditi, D.; Dikmen, I.; Birgonul, M. T. 2008. Effect of partner fit in international construction joint ventures, Journal of Management in Engineering 24(1): 12-20. https://doi.org/10.1061/(ASCE)0742-597X(2008)24:1(12)

Ozorhon, B.; Arditi, D.; Dikmen, I.; Birgonul, M. T. 2010. The performance of international joint ventures in construction, Journal of Management in Engineering 26(4): 209-222. https://doi.org/10.1061/(ASCE)ME.1943-5479.0000022

Paek, J.; Kim, J. 1993. Analyzing competitive position in the construction market of Eastern Europe, Journal of Management in Engineering 9(1): 38-51. https://doi.org/10.1061/(ASCE)9742-597X(1993)9:1(38)

Park, S. H.; Ungson, G. R. 1997. The effect of national culture, organizational complementarity, and economic motivation on joint venture dissolution, Academy of Management Journal 40(2): 279-307. https://doi.org/10.2307/256884

Park, H.; Han, S. 2012. Impact of inter-firm collaboration networks in international construction projects, in Construction Research Congress, 21-23 May 2012, West Lafayette, Indiana, United States, 1460-1470.

Park, H.; Han, S.; Rojas, E.; Son, J.; Jung, W. 2011. Social network analysis of collaborative ventures for overseas construction projects, Journal of Construction and Engineering Management 137(5): 344-355.

https://doi.org/10.1061/(ASCE)CO.1943-7862.0000301
Pryke, S. D. 2004. Analysing construction project coalitions: exploring the application of social network analysis, Construction Management and Economics 22: 787-797. https://doi.org/10.1080/0144619042000206533

Pryke, S. D. 2005. Towards a social network theory of project governance, Construction Management and Economics 23(9): 927-939. https://doi.org/10.1080/01446190500184196

Radziszewska-Zielina, E. 2010. Methods for selecting the best partner construction enterprise in terms of partnering relations, Journal of Civil Engineering and Management 16(4): 510-520. https://doi.org/10.3846/jcem.2010.57

Ruan, X.; Ochieng E. G.; Price, A. D. F.; Egbu, C. O. 2012. Knowledge integration process in construction projects: a social network analysis approach to compare competitive and collaborative working, Construction Management and Economics 30(1): 5-19. https://doi.org/10.1080/01446193.2011.654127

Son, J.; Han, S.; Rojas, E.; Park, H. 2010. Embeddedness and collaborative venture networks for overseas construction projects, in Construction Research Congress 2010, 8-10 May 2010, Banff, Alberta, Canada, 1325-1334.

Sridharan, G. 1997. Factors affecting the performance of international joint ventures - a research model, in The $1^{\text {st }}$ International Conference on Construction Industry Development, 9-11 December 1997, National University of Singapore, Singapore, 2: 84-91.

Tang, T. 2012. Knowledge transferring features in traditional construction project team in China: based on SNA, Technology and Investment 3: 230-235. https://doi.org/10.4236/ti.2012.34032

Turkish Contractors Association. 2014. General information [online], [cited 15 April 2014]. Available from Internet: http://www.tmb.org.tr/genel.php?ID=2

Turkish Ministry of Economy. 2014. Turkish contracting and engineering services [online], [cited 15 April 2014]. Available from Internet: http://www.economy.gov.tr/index. $\mathrm{cfm}$ ?sayfa=6FCC7802-FE1C-7ECF-E9C975B8EE928372

Ulubeyli, S.; Manisali, E.; Kazaz, A. 2010. Subcontractor selection practices in international construction projects, Journal of Civil Engineering and Management 16(1): 47-56. https://doi.org/10.3846/jcem.2010.04

Wambeke, B.; Liu, M.; Hsiang, S. 2012. Using Pajek and centrality analysis to identify a social network of construction trades, Journal of Construction and Engineering Management 138(10): 1192-1201. https://doi.org/10.1061/(ASCE)CO.1943-7862.0000524

Wong, K.; Unsal, H.; Taylor, E. J.; Levitt, E. R. 2010. Global dimension of robust project network design, Journal of Construction Engineering and Management 136(4): 442-451. https://doi.org/10.1061/(ASCE)CO.1943-7862.0000143

Yan, A.; Duan, J. 2003. Interpartner fit and its performance implications: a four-case study of U.S.-China joint ventures, Asia Pacific Journal of Management 20(4): 541-564. https://doi.org/10.1023/A:1026399211360

Zhang, L.; He, J.; Zhou, S. 2013. Sharing tacit knowledge for integrated project team flexibility: case study of integrated project delivery, Journal of Construction and Engineering Management 139(7): 795-804. https://doi.org/10.1061/(ASCE)CO.1943-7862.0000645 
Bartug Kemal AKGUL. He is a PhD student in Civil Engineering Department at Middle East Technical University, Turkey. He works as a civil engineer in a construction company. His primary research is social network analysis, company networks and collaboration strategies.

Beliz OZORHON. PhD, Associate professor in the Department of Civil Engineering at Bogazici University, Turkey. Her research initiatives focus on innovation management, international construction, joint ventures, strategic decision making, performance management, and knowledge management.

Irem DIKMEN. PhD, Professor and lecturer in the Construction Management and Engineering Division of the Civil Engineering Department in the Middle East Technical University. Her primary research interests include risk management, knowledge management, strategic management of construction companies and use of IT to improve the construction value chain. She also conducts extensive research in the area of risk management of BOT projects in Turkey. In addition to her research activities, she gives continuing education seminars and consultancy services to construction professionals about international business development and construction risk management.

M. Talat BIRGONUL. PhD, Professor and lecturer in the Construction Management and Engineering Division of the Civil Engineering Department in the Middle East Technical University. His primary research interests include engineering economy, international construction, construction planning, macroeconomic aspects of the construction industry and claim management. Apart from his academic activities, he acts as an expert witness in Turkish courts and Arbitral Tribunals and gives a claim management consultancy service to leading construction companies. Currently, he is acting as the director of Construction Management and Engineering Division of the Civil Engineering Department in the Middle East Technical University. 